\title{
Prosodic properties of formality in conversational Japanese
}

Ethan Sherr-Ziarko

University of Oxford

ethan.sherr-ziarko@stx.ox.ac.uk

This paper examines potential prosodic cues for level of formality in Japanese conversational speech using speech data gathered via one-on-one interviews. Based on previous work on the phonetic properties of formality in Japanese (Ofuka et al. 2000, Ito 2002), further studies of Korean (Winter \& Grawunder 2012) and Catalan Spanish (Hübscher, Borràs-Comes \& Prieto 2017), and on a lab-based pilot study, the study examined properties of $f_{0}$, intensity, pause frequency, and articulation rate via mixed effects regression models and a functional data analysis (Grabe, Kochanski \& Coleman 2007, Ramsay 2006). Analysis of the speech data shows significant relationships between a number of prosodic variables and level of formality, and suggests that some of these relationships may apply cross-linguistically.

\section{Introduction}

This paper investigates the prosodic properties of the informal register of conversational speech in Japanese, and how it compares to the formal register. Japanese was chosen as the language of study due to the large number of lexical and grammatical features used to mark both politeness and formality (Hinds 1976, 1978; Ide 1982, 1989; Makino 1983, Cook 1998, Sreetharan 2004), which made the process of assessing the level of formality in speech less subjective than in many other languages. In cross-linguistic terms (see e.g. Irvine 1979 for a general sociolinguistic discussion; Hinds 1976, 1978 for discussion specific to Japanese), formal speech can be defined as speech which is rigidly structured in terms of both what can be said and how it must be said, often occurs in formal social situations (such as meetings or presentations), and can be used to indicate the relative social positions of the speaker and listener in situations where the addressee has a higher social standing than the speaker (Irvine 1979: 776-779). These characteristics of f ormal speech do apply to Japanese, but different levels of formality in Japanese are also marked lexically in several ways, most notably verb endings, copular structure, and selection of formal vs. informal lemmas (Makino 1983). This leads to several lexically - and at times grammatically - distinct speech registers corresponding to different levels of formality (Hinds 1976). (1) lists several short sentences in Japanese which illustrate the types of lexical and grammatical contrasts which mark formality in Japanese.
(1) a. soko-ni
iki.mashita
soko-ni it.ta there-DAT go.PAST(formal)
there-DAT go.PAST(informal)
'Went there.' (formal)
'Went there.' (informal) 

b. nihongo-ga jyoozu desu
nihongo-ga jyoozu da Japanese-NOM skilled COPULA(formal) 'Good at Japanese.' (formal)
Japanese-NOM skilled COPULA(informal)
c. demo
iki.tai desu 'Good at Japanese.' (informal) but(formal) go.want COPULA (formal) but(informal) go.want INTENSIFIER '... but/even so I want to go.' (formal) '... but I want to go.' (informal)

The examples in (1) show how e.g. the choice of verb form (1a), copular verb (1b), and the selection of formal vs. informal lemmas or the addition of sentence-final particles (1c) can change the perceived formality of the sentence. This is not an exhaustive list of examples of lexical or grammatical items which indicate level of formality in spoken Japanese, but they do illustrate how formality can be judged post-hoc in Japanese, which was important to the design of the current study and is discussed further in Section 3.2.

Previous examinations of speech register in terms of politeness or formality in Japanese tended to be from the point of view of pragmatics (Ide 1982, 1989; Makino 1983, Matsumoto 1988, Pizziconi 2002), and these studies often focused more on contrasting politeness strategies in Japanese with those presented in more universal frameworks of politeness (Brown \& Levinson 1987) than on any prosodic properties of different speech registers. For the purposes of this study these pragmatic approaches were of less interest than those that focus on the different acoustic aspects of politeness in Japanese, but one aspect of these pragmatic studies that is important to address is the relationship between politeness and formality in Japanese.

\subsection{Formality and politeness in Japanese}

Throughout this paper, and occasionally in the previous literature, the concepts of FORMALITY and POLITENESS are often conflated, or treated as roughly equivalent in Japanese. It is not immediately obvious that it is justifiable to do so, as there is nothing in particular stopping formal speech from being either polite or impolite in many languages (Brown \& Levinson 1978), and issues of formality are often ignored or minimized in general frameworks of politeness (such as Brown \& Levinson 1987). However, pragmatic studies of politeness in Japanese (Ide 1982, 1989) have posited a close relationship between formal speech and polite speech in Japanese.

Although Ide (1982) was primarily concerned with women's speech in Japanese, that paper also proposed a series of rules which related the polite and formal registers of spoken Japanese. Specifically, one overriding rule was proposed: that speakers should 'Be polite in a formal setting' (Ide 1982: 371). Notably, this rule applies only to CONVERSATIONAL Japanese, and not strictly to written or scripted forms where informal and formal registers can sometimes combine in polite language. Ide (1982) proposes a relationship between formality and politeness wherein formal speech is always polite (based on the overriding rule), but informal speech can be either polite or 'plain' depending on context and lemma selection. Examples of this contrast in a sentence with otherwise identical meaning (after Ide 1982) are given in (2).

(2) a. Suzuki-si wa kyonen Amerika-e irassyai-masita. (formal, polite)

Suzuki-Mr. TOP last.year America-to go-PAST

(formal) (neutral) (formal/honorific)

'Mr. Suzuki went to America last year.'

b. Suzuki-san wa kyonen Amerika-e irrasyai-masita yo. (informal, polite)

Suzuki-Mr. TOP last year America-to go-PAST (intensifier)

(informal)

(formal/honorific) (informal)

$\begin{array}{lllllll}\text { c. Suzuki } & \text { wa } & \text { kyonen } & \text { Amerika } & \text { it-ta } & \text { yo. (informal, plain) } \\ \text { Suzuki } & \text { TOP } & \text { last year } & \text { America } & \text { to } & \text { go-PAST } & \text { (intensifier) }\end{array}$

(informal) 
The example in (2a) shows a typical formal, polite form of speech where formal forms of address ( $s i$ rather than san for 'Mr.') and verb forms are used. (2b) shows an example of how some properties of the informal register (such as the sentence final particle yo) can enter polite speech, while (2c) shows a sentence which is entirely in the informal register, drops the polite form of address (san) and uses an informal form of the verb 'to go'.

The critical observation from Ide (1982) is that in Japanese formality appears to be a property of politeness, and the two registers are closely related on a pragmatic level. Similarly, while speech containing aspects of the informal register is not always considered impolite, speech which contains entirely informal lemmas and grammatical forms will rarely if ever be considered polite (Ide 1989: 226-229). Because of this close relationship between polite and formal speech in Japanese, previous work which focused primarily on politeness rather than formality is still highly relevant to the current study. Although the relationship between INFORMAL speech and politeness is slightly more nebulous, it is reasonable to expect similar results when studying the prosodic properties of formal speech as were seen when polite speech was investigated. Furthermore, because informal speech seems to span different politeness categories, it is possible that analysis of the prosody of informal speech will produce a broad range of values that overlaps somewhat with the data observed for formal/polite speech.

\subsection{Studies of the prosodic properties of formality in Japanese}

Previous examinations of formal/polite speech in Japanese (Loveday 1981, Ohara 2001, Tsuji 2004) have indicated that polite speech in Japanese is characterized by an increased $f_{0}$ as compared to an overall mean for both polite and non-polite speech, as predicted both by Brown \& Levinson's (1987: 267-268) proposal of increased pitch as a universal indicator of increased politeness, and Ohala and Gussenhoven's frequency code (Ohala 1984, Gussenhoven 2002) which posits higher $f_{0}$ as a universal linguistic indicator of more formal and deferential speech. These studies largely focused on women's polite speech, and eschewed any attempt to examine informal speech alongside the formal examples, but there have been a few attempts at doing so.

Two previous studies of relevance here are Ofuka et al. (2000), an acoustic experiment regarding the prosodic cues to different levels of politeness in Japanese, and Ito (2002), a study of the effects of suprasegmentals (in this case $f_{0}$ and speech rate) on the perception of politeness in Japanese. Neither study is an exact parallel to the current one as both used elicited rather than conversational speech, but they can at least provide some initial insights into the possible prosodic properties of formality in Japanese.

Ofuka et al. (2000) involved eliciting a series of (read) utterances from speakers in a controlled laboratory setting, asking the subjects to deliver the utterances in both a 'formal' and then a 'casual' manner, and then using those recordings in a perceptual study to test the effects of different acoustic cues on a listener's perception of an utterance's politeness. The study was one of the first directly addressing the acoustic properties of casual versus formal speech, and the target features examined were narrow - only the speech rate of the final mora and the direction of $f_{0}$ movement (i.e. rise or fall in pitch) in the final mora were investigated.

The results of the study (Ofuka et al. 2000: 213-215) were that - as foreshadowed by another study of the perception of politeness in Japanese, Ogino \& Hong (1992) - both the direction of final $f_{0}$ movement and the speech rate of the final mora were used by listeners as indicators of the intended politeness of an utterance, where higher final $f_{0}$ and articulation rate indicated a more 'casual' utterance. From a production standpoint the results were somewhat ambiguous - though the majority of speakers had a higher $f_{0}$ in the less polite utterances, one showed the opposite pattern. Speech rate, however, was consistently higher in the less polite utterances. These findings are relevant to the current study, in that the possibility that $f_{0}$ and speech rate are both related to an utterance's level of formality was one of the hypotheses that this study sought to test (see Section 2 for further discussion). However, there are some 
aspects of Ofuka et al. (2000) that prevented it from being more of a foundation for the current study - firstly, only two sentences were tested, and both were questions, leading to a rather semantically narrow set of stimuli. Furthermore, the fact that the recorded stimuli were all read rather than spontaneous speech, and were also collected in a lab means that the current study analyzed a very different sort of speech stimuli, which may lead to contrasting results.

Ito (2002) differs from Ofuka et al. (2000) in several ways. Firstly, it made use of a speech corpus elicited at Chiba university (Aono et al. 1994) using the HCRC map task designed at the University of Edinburgh (Anderson et al. 1991) wherein speakers give directions to different points on a map to listeners of varying social relations to the speaker, hopefully eliciting utterances of varying levels of politeness based on the relative social standings of the conversational partners. Although these recordings were still made based on an artificial task, they should be far more natural than the read speech used in Ofuka et al. (2000). The results of Ito (2002) however were somewhat inconsistent. The study examined the overall $f_{0}$ and articulation rates of two speakers in the corpus, and these two speakers appeared to use different strategies to indicate level of formality. While one speaker appeared to increase both $f_{0}$ and articulation rate when speaking to a listener of lower status, the other speaker did not follow these patterns. Additionally, a perception experiment was conducted based on the speech of the speaker from the corpus who showed changes in $f_{0}$ and articulation rate, but listeners were found to be unable to consistently predict the level of formality based on the acoustic cues found in a single word (in this case /wakafimafita/ 'I understand'). Ito (2002) did nonetheless indicate a few points of relevance for the current study. One was that it does appear possible that speakers use increased $f_{0}$ and articulation rate to indicate formality, but also that speakers may not be entirely consistent, and that in general listeners may have difficulty using isolated cues to determine formality.

\subsection{Studies of the phonetic properties of formality in other languages}

There are several studies of the relationship between prosody and politeness in languages other than Japanese, such as Spanish, Mandarin, Korean, and English (see e.g. Álvarez \& Blondet 2003 for Venezuelan Spanish, Lin, Kwock-Ping \& Fon 2006 for Mandarin, Hübscher, Borràs-Comes \& Prieto 2017 for Catalan, and Hidalgo Navarro \& Cabedo Nebot, 2014 for a further overview). These previous studies indicated a number of possible acoustic properties of polite speech in languages other than Japanese, such as increased $f_{0}$ height and variability in Venezuelan Spanish interrogatives (Álvarez \& Blondet 2003), and longer phrase-final durations in Mandarin (Lin et al. 2006). Of these, the studies which are most likely to be relevant to the current study are Winter \& Grawunder (2012) - which investigated the relationship between acoustic factors and formality in Korean - and Hübscher et al. (2017), which was a similar study investigating Catalan Spanish. The reasons for their relevance are that, firstly, they were concerned with FORMALITY rather than strictly with POLITENESS, which mirrored the current study. As the relationship between formality and politeness in other languages is not necessarily as clear as it is in Japanese, this is a critical point. Secondly, Winter \& Grawunder (2012) appeared particularly relevant as it has been observed that there are some similarities in prosodic structure between Korean and Japanese, particularly at the level of the intonational and accentual phrases (see Venditti, Jun \& Beckman 2014, and various chapters in Kubozono 2015), and so making comparisons between the prosody of the two languages is not entirely far-fetched.

Winter \& Grawunder (2012) collected speech of different levels of formality via a roleplaying task, where subjects were asked to either leave a message on a cell phone voice mail, or to make a direct request of someone in person. Both scenarios were used to produce examples of formal and informal speech. The acoustic properties - including mean, range, and SD of $f_{0}$ and intensity, harmonics, articulation rate, pause count, filler count, and breath intakes - of the different levels of formality were analyzed and compared using mixed effects regression models. Significant main effects were found for mean, SD, and range of $f_{0}$ ( $p<.01$ for all), 
articulation rate $(p<.05)$, and filler count $(p<.001)$, wherein all were significantly higher in informal than in formal speech. Following this 2012 study of Korean, Lucien Brown, Bodo Winter, Kaori Idemaru and Sven Grawunder (Brown et al. 2014) also conducted a perception experiment which tested the salience of the prosodic variables analyzed in Winter \& Grawunder (2012) to Korean and English listeners' perception of the honorific speech register in Korean. While their speech stimuli were read rather than spontaneous, Brown et al. (2014) did find that both Korean and, to a lesser extent, English speaking listeners were able to use prosodic cues to correctly identify speech to a status superior or inferior at a rate greater than chance. This result implies that certain prosodic properties of different levels of politeness/formality could be present cross-linguistically.

Hübscher et al. (2017), a study of Catalan Spanish, structured similarly to Winter \& Grawunder (2012) - excepting that all speech data was formulated as requests - also found significantly higher mean $f_{0}$ in casual speech $(p<.001)$. This result further contrasted the prediction of the FREQUENCY CODE (Ohala 1984, Gussenhoven 2002) which states that higher $f_{0}$ should correlate with formal and deferential speech. Hübscher et al. (2017) also found that there was a higher pause rate, lower intensity, and slower speech rate in formal speech, which they termed 'prosodic mitigation'. The similarity of these results to Winter \& Grawunder (2012) indicated that this strategy of prosodic mitigation is used in multiple languages in the expression of formality, and that the relevant variables were worth investigating in the current study.

Although the results of Winter \& Grawunder (2012) and Brown et al. (2014) were not necessarily enough by themselves to hypothesize that the same results would be seen in the current study, the observed similarity between the prosody of the two languages allowed them to serve as a point of reference. The similar results of Hübscher et al. (2017) do suggest some possible cross-linguistic patterns in the relationship between prosody and formality in speech, and the fact that many aspects of $f_{0}$ (mean, SD, and range) and intensity (SD and range) appeared to co-vary significantly with changes in formality in both Korean and Catalan indicated that it was worth investigating the relationship between these variables and formality in Japanese to a similar (or greater) level of depth. Additionally, the fact that many of the tested phonetic parameters were higher in informal speech was of interest, as this result could help better inform the hypotheses of the current study as they related to the expected relationship between prosody and formality. Comparing the results of this study of Japanese to Winter \& Grawunder (2012) and Hübscher et al. (2017) can also provide some insight as to the possible presence of some of these phonetic cues to formality across multiple languages, as if the results are very similar it could indicate that there are cross-linguistic tendencies in how prosody relates to speech register.

\section{Research questions and hypotheses}

This study investigated two related research questions:

(i) Do speakers of Japanese make use of changes in prosody to help communicate their intended level of formality in conversation? and, if that was the case,

(ii) What specific differences in the prosody are used by speakers to distinguish different levels of formality?

These questions have been partially addressed by a pilot study ${ }^{1}$ (Sherr-Ziarko 2016) which found a significant relationship of mean $f_{0}$ and utterance duration to formality. The current

\footnotetext{
${ }^{1}$ The pilot study (described in more detail in Sherr-Ziarko 2016) was a lab-based experiment which involved analyzing the prosody of utterances where different levels of formality in subjects' speech were elicited indirectly via the inclusion of lexical items indexical of the informal register of speech in Japanese.
} 
study investigated questions (i) and (ii) using a corpus of conversational Japanese speech gathered in one-on-one interviews, and the formality of each utterance was judged based on a consistent set of criteria, discussed further in Section 3.2.

The results of the pilot study, together with the results from the previous cross-linguistic literature, led to two hypotheses: firstly, that speakers do use changes in prosody to express different levels of formality in speech, and secondly that differences in properties (including mean, $\mathrm{SD}$, and range) of $f_{0}$, articulation rate, intensity, and pause frequency would co-vary significantly with the level of formality in speech. Each of these variables was expected to be higher in informal speech, excepting pause frequency which was predicted to be higher in formal speech. The first hypothesis has already seen some support from the results of the pilot study, and previous studies showing a relationship between prosody and politeness in Japanese (Ofuka et al. 2000, Ito 2002). This study tested the hypothesized relationship between prosody and formality on a much larger scale, and critically in conversational rather than read or elicited speech, hopefully leading to more robust results. The second hypothesis was based largely on the cross-linguistic results from Korean found in Winter \& Grawunder (2012), as that study was the most methodologically similar to the current one, although the methodology for obtaining speech data from different levels of formality varied (see Section 3 for further discussion).

\section{Data collection and annotation}

As the goal of the experiment was primarily to examine the properties of conversational Japanese, the decision was made to conduct a corpus-based experiment. Although any speech recorded outside of natural conversation was likely to fall somewhat short of the ideal level of naturalness for this study, spontaneous speech gathered for a corpus was likely to come much closer to the desired speech registers than speech obtained in a lab. Additionally, speech corpus data has in the past produced significant results in phonetic studies where similar lab-based experiments did not (such as Gahl 2008 vs. Guion 1995).

Initial investigations into possible corpora of spoken Japanese revealed two potentially viable sources: the Corpus of Spontaneous Japanese (CSJ; Maekawa 2003), and the Chiba University three-way conversation corpus (Den \& Enomoto 2007). Both corpora were gathered in Japan, and contain entirely spontaneous speech. The CSJ contains mainly monologues, and presentations, while the Chiba corpus contains short conversations across three participants. Both corpora are very well annotated, with detailed segment meta-data and pitch tracking information, but both also have shortcomings.

The main shortcoming of the CSJ for this study was that it although it contains millions of words, it contained very little speech that could be considered informal, and essentially none that could be considered conversational. The Chiba corpus on the other hand contained entirely conversational speech of varying levels of formality, but unfortunately only consisted of roughly 30 minutes of recordings, which was not sufficient for the scope of this study. Because of the shortcomings of the available corpora, and in order to have greater control over the collection methods and content of the data, the decision was made to create a new small corpus of conversational Japanese speech.

\subsection{Data collection methodology}

The speech data for this study was collected at the NINJAL institute in Tachikawa-shi, Japan via one-on-one interviews between the experimenter and subjects. The interviewer was a non-native speaker of Japanese with a high-level of proficiency, and subjects were 10 native speakers of Japanese aged 31-45 years (five male, five female). The age of subjects was kept below 50 years in order to minimize any potential influence of the effects of age on $f_{0}$ 
(Harrington, Palethorpe \& Watson 2007), and all subjects were speakers of the Tokyo dialect of Japanese (born and raised in the Tokyo area up to age 18 years) in order to reduce any possible effects on $f_{0}$ from different dialects (Kubozono 2012). Interviews were conducted in a lounge setting rather than a recording booth or lab in order to encourage a more natural, conversational style of speech. Recordings were single-channel mono, made at $48 \mathrm{kHz}, 16$ bit PCM and used a clip-on microphone.

The format of the interviews was similar to a sociolinguistic interview (Labov 1972) but with less control of the topics discussed, and each subject was recorded for $\sim 30$ minutes. All interviews began with self-introductions from both the interviewer and the subject, which were generally quite formal, and then proceeded naturally to other topics as they arose, with the interviewer gradually modulating their speech register to a more informal level to encourage the subject to follow. In general, this resulted in a pattern where the first five minutes of the interview consisted mainly of formal speech, minutes 5-10 consisted of a mix of formal and informal speech, with subjects sometimes code-switching within utterances, and the remainder of the interview consisting of mostly informal speech. Although the topics discussed in the interviews were not entirely consistent from subject-to-subject, certain topics were consistently touched upon, and are listed in the appendix.

In total this resulted in $\sim 5$ hours of recorded speech for analysis.

\subsection{Data annotation}

To ensure analysis of the correct portions of the recorded data, the extended recordings were annotated as follows. As the target of the experiment was only utterances by the subjects, these targets had to be separated from the interviewer's speech. This was accomplished by manually labeling the intervals of the subjects' utterances in a Praat text grid. Interval labels were created for each of the subject's utterances, with the following exceptions:

- Isolated filler interjections (such as /e:/ or /a:/) were not included.

- Isolated laughter was not included, unless it occurred clause-internally.

The interval boundaries were placed either at clause boundaries in the case of uninterrupted utterances, or at turn-taking boundaries (the boundary between the end of the first speaker's turn and the start of the second speaker's) in the case of back-and-forth conversation containing fragments.

The number of lexical moras within each clause or fragment was manually counted in order to allow the calculation of articulation rate data. Pauses in speech were not included in the mora count, but were instead counted separately to allow for the analysis of pause frequency in different levels of formality.

The speech within each labeled interval was judged to be either formal, or informal. This judgment was initially made by the experimenter, and once all intervals were assessed, 16 linguistically naive native speakers of Tokyo Japanese (six male, 10 female, aged 20-31 years) were later asked to judge the formality of randomly selected intervals in order to confirm the judgments. In any cases where there were differences in judgments - which occurred in roughly $2.5 \%$ of intervals - the assessment of the native speaker was followed. Although any judgment of the level of formality of a given utterance is to some degree in the eye of the beholder, because the determination of levels of formality was very important to this study a consistent set of criteria to judge formality was established (Table 1).

The criteria in Table 1 were determined largely by previous examinations of lexical items and phonological forms indexical of different registers of formality in Japanese (Hinds 1976, Ide 1982, Makino 1983, Cook 1998, Okamoto 1999) and of observational evidence of spoken Japanese. Once all the speech data was labeled, it was then automatically segmented into separate .wav files (one per labeled interval). $f_{0}$ and intensity values were calculated for each .wav file at $10 \mathrm{~ms}$ intervals using a Praat script, and these values were then used to calculate the means, SDs, and ranges for each recording. Articulation rate and pause frequency data 
Table 1 Criteria used in determining utterance formality.

\begin{tabular}{|c|c|c|}
\hline Criteria & Formal example & Informal example \\
\hline Copular verb & /desuc/ 'to be' & /da/ 'to be' \\
\hline Verb forms & / SimaJita/ 'did' & / Sita/ 'did' \\
\hline Sentence-final particles & /-wa/ & /-jo/ \\
\hline Question particles & $/-\mathrm{ka} /$ & /-kai/ \\
\hline Under/over articulation & /tsuomałanai/ 'boring' & /tsumman:ai/ 'boring' \\
\hline Indexical word forms & /jahaıil/'... after all' & /jap:a/ '... after all' \\
\hline Honorifics & /ika_emasu/ ' to go (HoN)' & /ikuo/ 'to go' \\
\hline
\end{tabular}

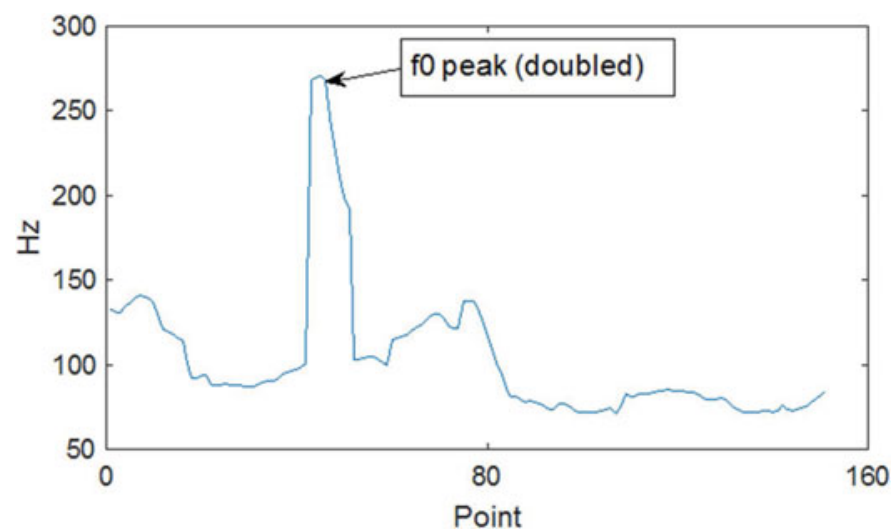

Figure 1 (Colour online) An fo vector showing a pitch-doubling error. The $x$-axis shows points at $10 \mathrm{~ms}$ intervals, while the $y$-axis shows $f_{0}$ values at each point in $\mathrm{Hz}$.

was calculated using bash scripts. In total, this resulted in 2,497 utterances, of which 418 were formal, and 2,079 were informal. There were 1,230 utterances by female subjects and 1,267 by male subjects.

\section{$4 f_{0}$ measurement and correction}

As the measurement and analysis of $f_{0}$ was central to this study, it was important to be certain that the $f_{0}$ measurements were as accurate as possible. However, the initial measurements from Praat were not entirely reliable, due to pitch peak (and trough) estimation errors (i.e. pitch doubling or halving) (Keelan, Lai \& Zechner 2010), as can be seen in Figure 1. To help overcome this problem, an automated Matlab script to diagnose and fix pitch-doubling errors in $f_{0}$ vectors was developed.

In order to ensure that $f_{0}$ was accurately analyzed, the following method was used to correct pitch-doubling errors. Similar to the method used by $\mathrm{Xu}$ (2013), pitch peak/trough estimation errors were diagnosed and corrected by examining the absolute value of the first differences of the vector, and searching for changes that fall outside of an expected range of tolerance. After calculating the first differences and testing a Matlab script which attempted to diagnose pitch-tracking errors, and testing it on a number of $f_{0}$ vectors, a threshold of three times the mean of the absolute value (i.e. with positive and negative differences treated the same) of the first differences was arrived at. Because the script checked the absolute value of the first differences rather than only looking for an increase or decrease, the script served to diagnose pitch halving and well as doubling errors. 

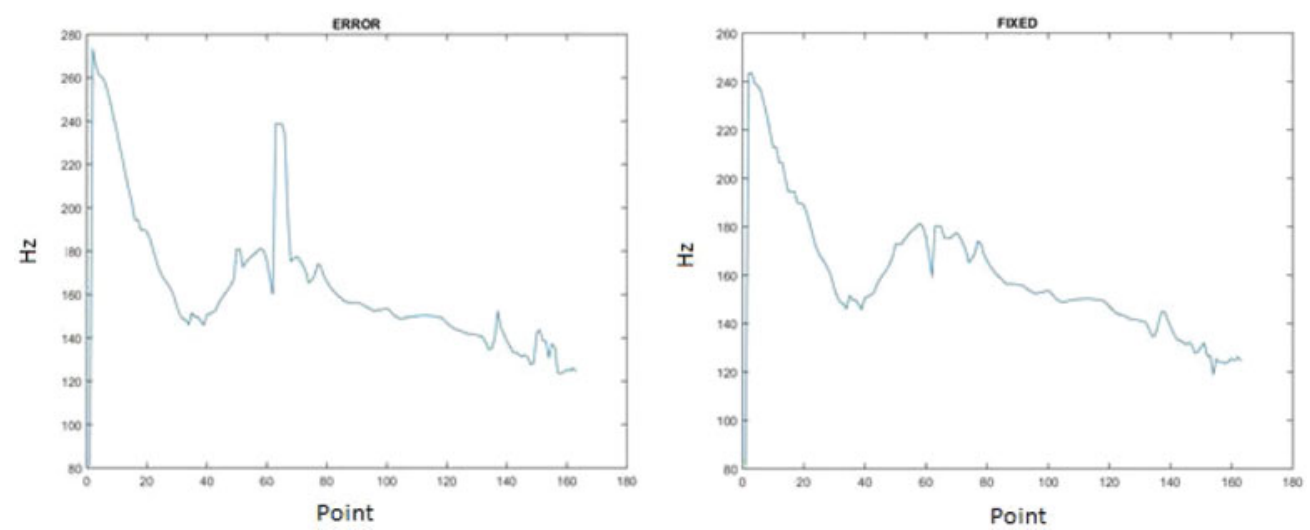

Figure 2 (Colour online) to vectors with a pitch-doubling error (on the left) and after automatic correction (on the right).

After testing for errors, the vector was then corrected by adjusting the values between two changes in the slope of the vector outside of the set level of tolerance by the difference between the $f_{0}$ value at the peak of the error and the point immediately after the end of the error. The script will avoid correcting extremely long errors (defined as lasting for more than $15 \%$ of the total length of the vector); this is because most of these sudden drops or increases in $f_{0}$ followed by an extended portion of the vector that appears normal generally result from the fact that undefined $f_{0}$ values given by the Praat pitch tracking are ignored, and therefore any gaps in voicing are not represented in the vector. This leads to there being apparently sudden changes in the $f_{0}$ vector which are actually correct. Figure 2 shows an example of a $f_{0}$ vector which has been corrected by the Matlab script. With those fixed $f_{0}$ vectors created, it was possible to move on to the next step of analyzing the data.

\section{Data analysis}

The variables analyzed in this study were the mean, SD, and range of both $f_{0}$, and intensity, as well as articulation rate, and pause frequency. $f_{0}$ range was calculated as equal tempered semitones relative to the minimum and maximum pitch $\left(12 * \log 2\left(\max f_{0} / \min f_{0}\right)\right)$, and intensity range was calculated as the difference between the minimum and maximum $\mathrm{dB}$ of the recording. As discussed in Section 2, the hypothesis the study tested is that $f_{0}$, intensity, and articulation rate are significantly higher in informal speech than in formal speech, while pause frequency is higher in formal speech. Table 2 shows a summary of all these variables broken down by level of formality.

\subsection{Statistical methods}

The statistical analyses in this study were conducted using linear mixed effects regression models (Bates et al., 2015) in R (R Core Team, 2017), as the variables listed in Table 2 lack independence within subjects. The models used (except where otherwise noted) are constructed as shown in (3):

(3) $[$ dependent variable $] \sim$ formality + gender + formality $*$ gender $+(1+$ formality/subject $)$

This model can be read as follows: a dependent variable as a function of the fixed factors of formality and gender, as well as the possible interaction of formality and gender. It also 
Table 2 Descriptive statistics of all the variables examined in this study. $f_{0}$ range is measured in equal tempered semitones (cents (c)), articulation rate in moras per second $(\mathrm{m} / \mathrm{s})$ and pause frequency measures the number of pauses per utterance.

\begin{tabular}{|c|c|c|c|c|c|c|c|c|c|}
\hline \multirow[b]{3}{*}{ Variable } & & \multicolumn{8}{|c|}{ Summary of data } \\
\hline & & \multicolumn{4}{|c|}{ Mean } & \multicolumn{4}{|c|}{ SD } \\
\hline & & Formal & Informal & Male & Female & Formal & Informal & Male & Female \\
\hline \multirow[t]{3}{*}{ Intensity } & Mean & $72.1 \mathrm{~dB}$ & $74.1 \mathrm{~dB}$ & $74.2 \mathrm{~dB}$ & $73.3 \mathrm{~dB}$ & $5.1 \mathrm{~dB}$ & $5.4 \mathrm{~dB}$ & $5.3 \mathrm{~dB}$ & $5.0 \mathrm{~dB}$ \\
\hline & SD & $7.6 \mathrm{~dB}$ & $7.8 \mathrm{~dB}$ & $7.6 \mathrm{~dB}$ & $8.0 \mathrm{~dB}$ & $1.7 \mathrm{~dB}$ & $1.8 \mathrm{~dB}$ & $1.7 \mathrm{~dB}$ & $1.6 \mathrm{~dB}$ \\
\hline & Range & $29.0 \mathrm{~dB}$ & $30.7 \mathrm{~dB}$ & $29.4 \mathrm{~dB}$ & $31.4 \mathrm{~dB}$ & $5.9 \mathrm{~dB}$ & $6.0 \mathrm{~dB}$ & $6.1 \mathrm{~dB}$ & $5.6 \mathrm{~dB}$ \\
\hline \multirow[t]{3}{*}{$f_{0}$} & Mean & $151.2 \mathrm{~Hz}$ & $168.1 \mathrm{~Hz}$ & $126.2 \mathrm{~Hz}$ & $205.4 \mathrm{~Hz}$ & $45.2 \mathrm{~Hz}$ & $51.0 \mathrm{~Hz}$ & $29.5 \mathrm{~Hz}$ & $33.0 \mathrm{~Hz}$ \\
\hline & SD & $27.5 \mathrm{~Hz}$ & $36.0 \mathrm{~Hz}$ & $29.1 \mathrm{~Hz}$ & $40.3 \mathrm{~Hz}$ & $13.5 \mathrm{~Hz}$ & $15.2 \mathrm{~Hz}$ & $13.2 \mathrm{~Hz}$ & $15.1 \mathrm{~Hz}$ \\
\hline & Range & $14.01 \mathrm{c}$ & $16.14 \mathrm{c}$ & $16.16 \mathrm{c}$ & $15.4 \mathrm{c}$ & 5.97 c & $6.30 \mathrm{c}$ & $6.22 \mathrm{c}$ & $5.92 \mathrm{c}$ \\
\hline Articulation rate & & $6.1 \mathrm{~m} / \mathrm{s}$ & $7.6 \mathrm{~m} / \mathrm{s}$ & $7.1 \mathrm{~m} / \mathrm{s}$ & $7.5 \mathrm{~m} / \mathrm{s}$ & $1.8 \mathrm{~m} / \mathrm{s}$ & $1.6 \mathrm{~m} / \mathrm{s}$ & $1.8 \mathrm{~m} / \mathrm{s}$ & $1.6 \mathrm{~m} / \mathrm{s}$ \\
\hline Pause frequency & & 0.80 & 0.35 & 0.46 & 0.39 & 0.94 & 0.63 & 0.75 & 0.67 \\
\hline
\end{tabular}

Table 3 Summary of modeling results for the variables in this chapter. Estimate is an estimate of the overall slope of the change in the linear model based on the fixed factor, with the variance caused by the random effects taken into account. Values for interaction terms are not reported as none were significant according to model comparison.

\begin{tabular}{|c|c|c|c|c|c|c|}
\hline \multirow[b]{3}{*}{ Variable } & & \multicolumn{5}{|c|}{ Modelling results } \\
\hline & & \multicolumn{3}{|c|}{ Model summary } & \multicolumn{2}{|c|}{ Model comparison } \\
\hline & & Estimate & Std. Error & t-value & $\chi^{2}(2)$ & $\operatorname{Pr}\left(>\chi^{2}\right)$ \\
\hline Intensity & $\begin{array}{l}\text { Mean } \\
\text { SD } \\
\text { Range }\end{array}$ & $\begin{array}{l}-2.65 \\
-0.32 \\
-2.10\end{array}$ & $\begin{array}{l} \pm 0.36 \\
\pm 0.12 \\
\pm 0.41\end{array}$ & $\begin{array}{l}-7.28 \\
-2.54 \\
-5.08\end{array}$ & $\begin{array}{r}21.87 \\
5.47 \\
17.27\end{array}$ & $\begin{array}{c}<.001 \\
\text { n.S. } \\
<.001\end{array}$ \\
\hline$f_{0}$ & $\begin{array}{l}\text { Mean } \\
\text { SD } \\
\text { Range }\end{array}$ & $\begin{array}{l}-0.04 \\
-9.08 \\
-2.01\end{array}$ & $\begin{array}{l} \pm 0.03 \\
\pm 1.24 \\
\pm 0.57\end{array}$ & $\begin{array}{l}-9.79 \\
-7.34 \\
-3.52\end{array}$ & $\begin{array}{l}35.49 \\
23.04 \\
12.18\end{array}$ & $\begin{array}{r}<.001 \\
<.001 \\
.002\end{array}$ \\
\hline Articulation rate & & -1.12 & \pm 0.11 & -9.92 & 23.72 & $<.001$ \\
\hline Pause frequency & & 0.48 & \pm 0.09 & 5.54 & 19.03 & $<.001$ \\
\hline
\end{tabular}

includes random intercepts and slopes (of formality) for each individual speaker in the corpus. Full results of all the modelling analyses described in this section are found in Table 3 -results reported include slope estimates and standard errors for the main effect of formality, $p$-values (if significant) for the main effect, and $t$-values for the fixed effects in the models.

\subsection{Articulation rate}

It is immediately apparent from Table 2 that the mean articulation rate of informal speech was quite a bit higher than that of formal speech. Model comparison using a likelihood-ratio test of a linear mixed-effects model in $\mathrm{R}$, as in (3), showed a significant relationship between articulation rate and formality, with no significant effect of gender, or interaction between formality and gender. $(\chi 2(2)=23.649, p<.001$, rate changes by -1.37 moras $/$ second \pm 0.2 moras/second standard error in formal speech.)

This initial finding agreed with the results of the pilot study, and of previous acoustic studies of Japanese informal speech (Ofuka et al. 2000, Ito 2002) as well as the results of 


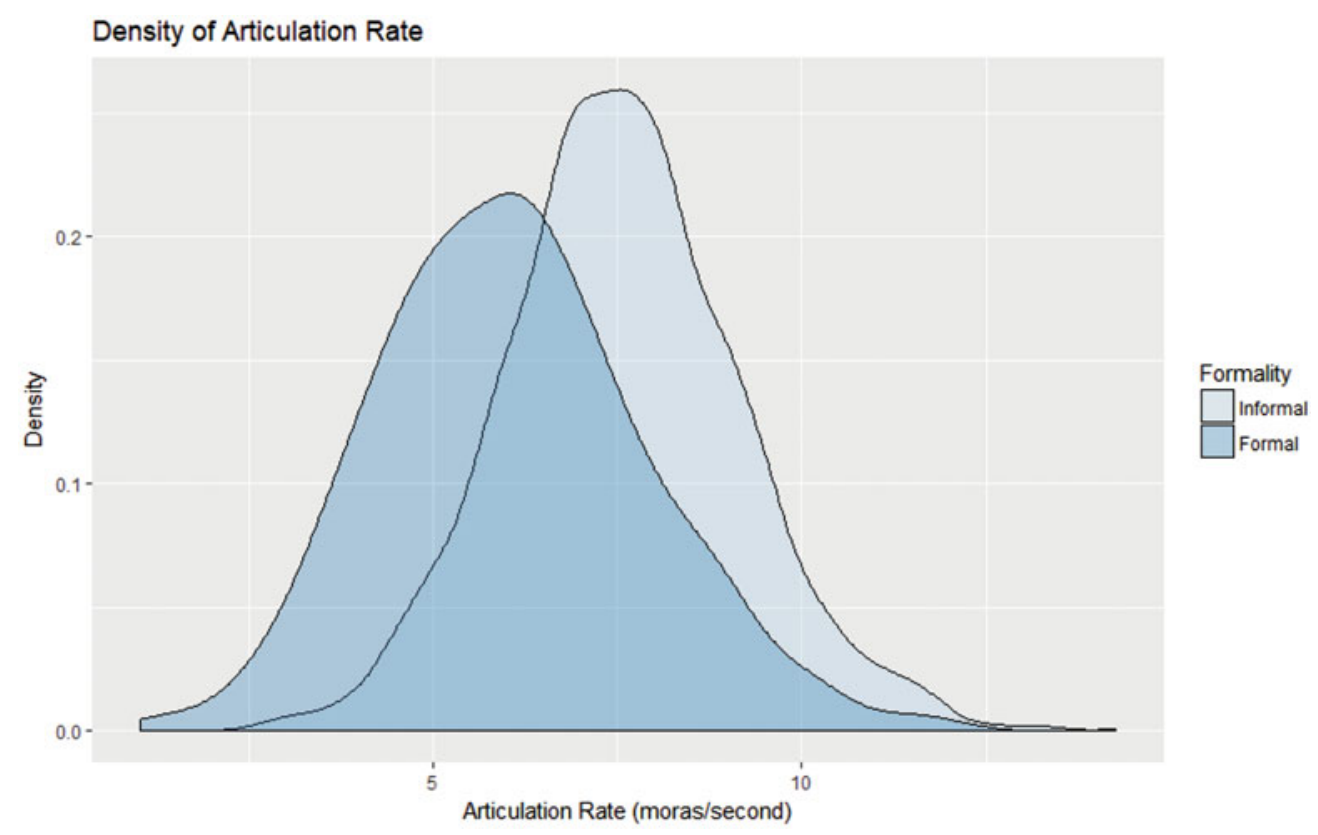

Figure 3 (Colour online) Density plot of articulation rate in informal and formal speech.

Winter \& Grawunder (2012) for Korean. However, there was one caveat to this seemingly straightforward analysis that must be mentioned. Figure 3 shows a density plot of articulation rates in both formal and informal speech.

The basic shape of this plot is as hypothesized - the mean articulation rate for informal speech was higher, and values were clustered more towards the higher end of the curve. However, the fact that formal speech was more widely distributed (as evidenced by the higher $\mathrm{SD}$ in Table 2), and reached a lower minimum raised the question of whether something else was causing this wider distribution. Specifically, if pause frequency is, as hypothesized, higher in formal speech, then it is possible that it was acting as a confound. To test this, both pause frequency and the interaction of pause frequency $\times$ formality were added to the mixed effects model to test if formality remained a significant factor.

Although analysis of such a model does show a significant relationship between pause frequency and articulation rate (i.e. more or less pausing correlates with differences in articulation rate), the interaction term was non-significant.

\subsection{Pause frequency}

The analysis of articulation rate, as well as the mean values in Table 2 showed some initial evidence that subjects paused more frequently in formal speech. Modelling analysis shows a significant relationship between pause frequency and formality, with no significant effect of gender or the interaction term. $(\chi 2(2)=19.03, p<.001$, pause frequency changes by +.48 pauses/utterance \pm .08 standard error in formal speech.) Based on the analysis of articulation rate in Section 5.2 it did not appear that the two variables were confounded, and so the results appeared to show that subjects paused more frequently in formal speech, following Winter \& Grawunder (2012) and Hübscher et al. (2017). 


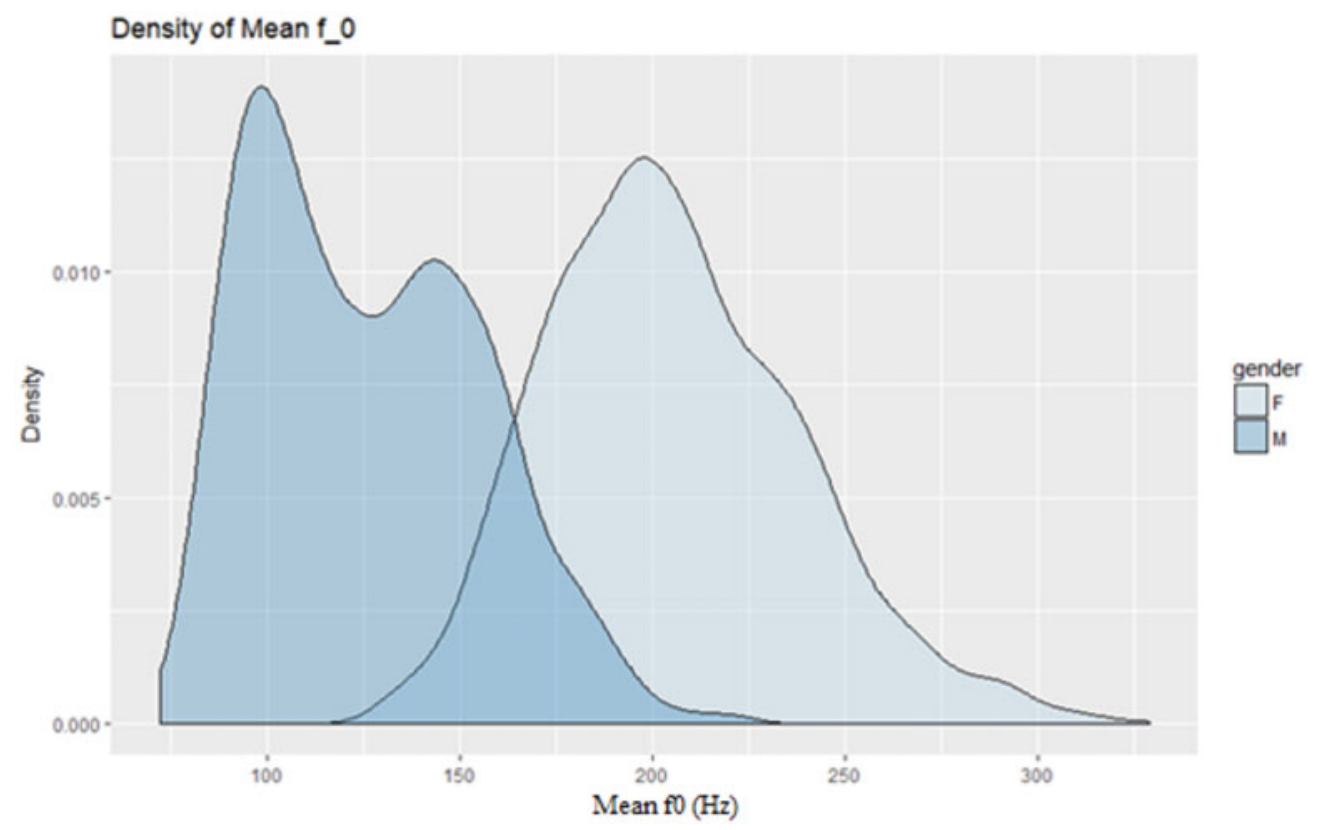

Figure 4 (Colour online) Density plot of mean fo for male and female speakers.

\subsection{Intensity}

Intensity was calculated for each recording at $10 \mathrm{~ms}$ intervals using Praat, and the mean, SD, and range of intensity was calculated from each of those vectors. Intensity was measured in dB SPL (a lognormal scale of power) and was not further scaled as any incidental changes in intensity were of interest to the study. Intensity range was calculated as the difference between the maximum and minimum intensities in the recording. While the results of the analyses of articulation rate and pause frequency largely corresponded to the results from Winter \& Grawunder (2012) for Korean, the results in Japanese for variables related to intensity were somewhat different. Both mean intensity $(\chi 2(2)=19.234, p<.001$, intensity changes by $-2.2 d B \pm 0.3 d B$ standard error in formal speech) and intensity range $\left(\chi^{2}(2)=16.417\right.$, $p<.001$, intensity range changes by $-1.8 d B \pm 0.3 d B$ standard error in formal speech) show a significant relationship with formality, while there is no significant effect of SD. There are no significant interactions between gender and any aspect of intensity.

\section{$5.5 \quad t_{0}$}

$f_{0}$ was calculated at $10 \mathrm{~ms}$ intervals of each recording in Praat, and then corrected via the Matlab script described in Section 4. $f_{0}$ range was calculated as equal tempered semi-tones (i.e. 1/12th of an octave) relative to the maximum and minimum pitch of each recording. Based on the values in Table $2 f_{0}$ also appeared to be a potentially significant cue to the formal vs. informal contrast, but there were some issues with the data that are important to note. Figure 4 shows a density plot of mean $f_{0}$ for each gender.

It is readily apparent that $f_{0}$ is not normally distributed, particularly for male speakers, who appear to have two separate peaks of density. Although it is possible that this data would still be interpretable in a linear mixed effects model with the inclusion of sufficient random factors to normalize the residuals (Bates et al. 2015), it is in general better statistical practice to either normalize the data, or (in the case of binary data as in the current study) make use of generalized linear mixed effects models (see Bolker et al. 2009 for some discussion). 
Although there is disagreement surrounding the appropriateness of a strictly logarithmic scale for $f_{0}$ as it relates to human pitch perception (see e.g. Zwicker 1961, Moore \& Glasberg 1983, Nolan 2003), because log transforming $f_{0}$ has some experimental basis (Fujisaki \& Hirose 1984, Henton 1989, Nolan 2003) and is statistically motivated in this case, the mean $f_{0}$ values were $\log _{10}$ transformed for analysis. This was not an issue for the SD of $f_{0}$, or for $f_{0}$ range as both of those variables were normally distributed (and range was already on a logarithmic scale).

The results of the analysis showed a significant effect of mean $f_{0}(\chi 2(2)=35.49, p<$ .001 , estimate $-0.04 \pm 0.03), \mathrm{SD}$ of $f_{0}(\chi 2(1)=23.04, p<.001$, SD changes by $-9.09 \mathrm{~Hz}$ $\pm 1.24 \mathrm{~Hz}$ standard error in formal speech $)$, and $f_{0}$ range $\left(\chi 2(2)=12.18, p<.001, f_{0}\right.$ range changes by -2.01 semitones \pm 0.57 semitones standard error in formal speech). There were no significant interaction terms with gender.

While the results described in this section provided strong statistical support for the hypotheses described in Section 2, it is still possible to provide further depth to the analysis of $f_{0}$, and particularly $f_{0}$ range. In order to do so, a FUNCTIONAL DATA ANALYSIS was adopted.

\section{Functional data analysis}

Functional data analysis refers to a methodology whereby continuous functions (in this case orthogonal polynomials) are fitted to vectors, and the coefficients of the fitted polynomials are related to linguistic variables (Grabe et al. 2007, Ramsay 2006). This was done by using the polyfit function in Matlab to initially fit cubic functions to $f_{0}$ vectors.

First, the pitch tracking data which had been fixed by the script described in Section 4 was taken, and the vectors were normalized using the operation in (4), and then normalized for time (where $y$ is the original $f_{0}$ vector, and $y n$ is the normalized vector, centered on 0 ).

(4) $y n=\frac{y}{\operatorname{mean}(y)-1}$

In order to further determine the goodness of fit of the function, the sum of the squared differences between the fitted function and the normalized data vector was calculated using the operation in (5) (where $y f$ is the fitted function).

$$
\text { (5) } d=\frac{\sum_{(y f-y n)^{2}}}{\text { length(yn) }}
$$

However, an examination of how the resulting functions fitted to some of the longer utterances revealed an issue with this initial approach. When a cubic function was fitted to each utterance, the mean $d$ - as in (5) - was 0.097 . For reference, Figure 5 shows an example of a fitted cubic function for a random utterance from the data with a $d$ equaling approximately 0.1 . As can be seen clearly from Figure 5, with a $d$ of 0.1 , the fitted function was essentially meaningless, fitting to almost no part of the original vector. An average difference of this magnitude meant that there was little chance of obtaining any meaningful data.

Closer examination of the fitted functions compared to the $f_{0}$ contours made it apparent that a $d$ of around $0.02-0.04$ was ideal for the function to fit accurately and smooth out some of the jagged movement of the vector not fixed by the script described in Section 4 . Figure 6 shows an example of such a function.

The function in Figure 6 fits the vector reasonably well, and also appears to smooth out some small, rapid jumps and drops in $f_{0}$ that would not be detected as errors by the script in Section 4. In order to achieve a $d$ of 0.02-0.04 for all utterances, another function was written in Matlab which began by attempting to fit a pintic ( 5 degree) function to each vector, tested the goodness of fit of the function after fitting, and then either increased the degree 


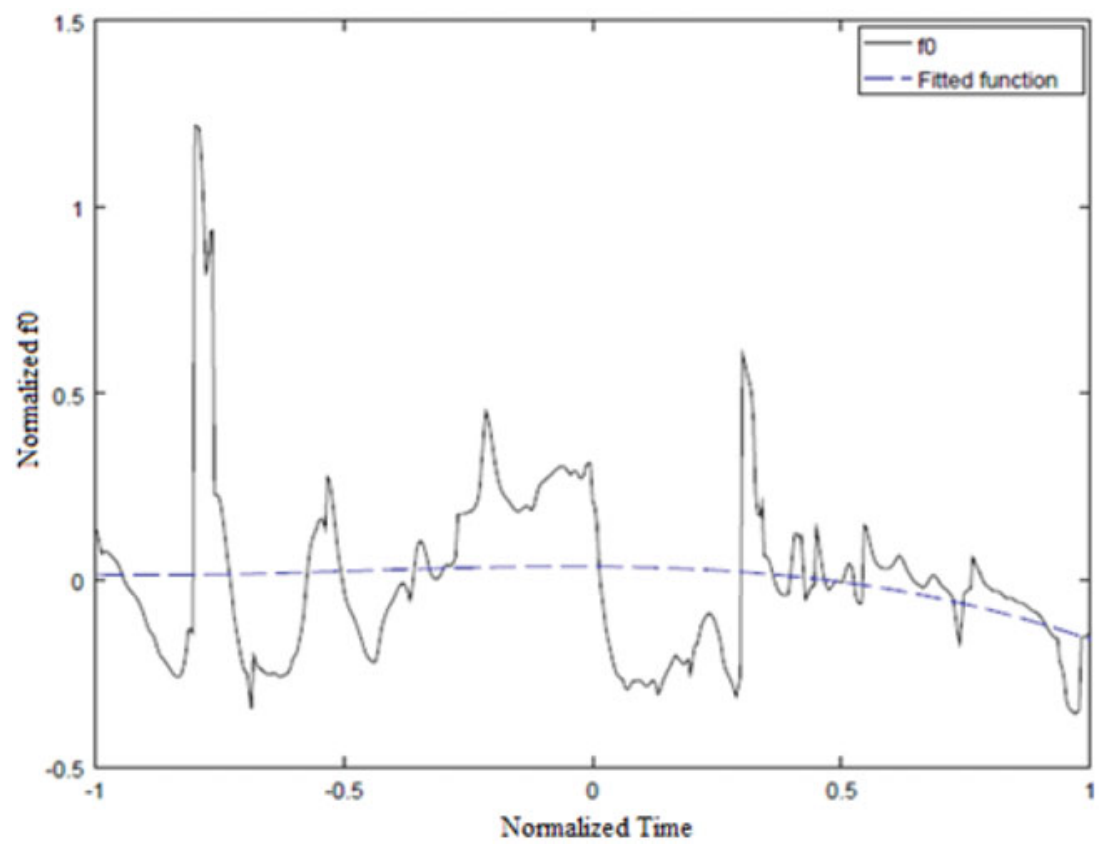

Figure 5 (Colour online) An example of a fitted function (indicated by the dashed line) with a $d$ of 0.1.

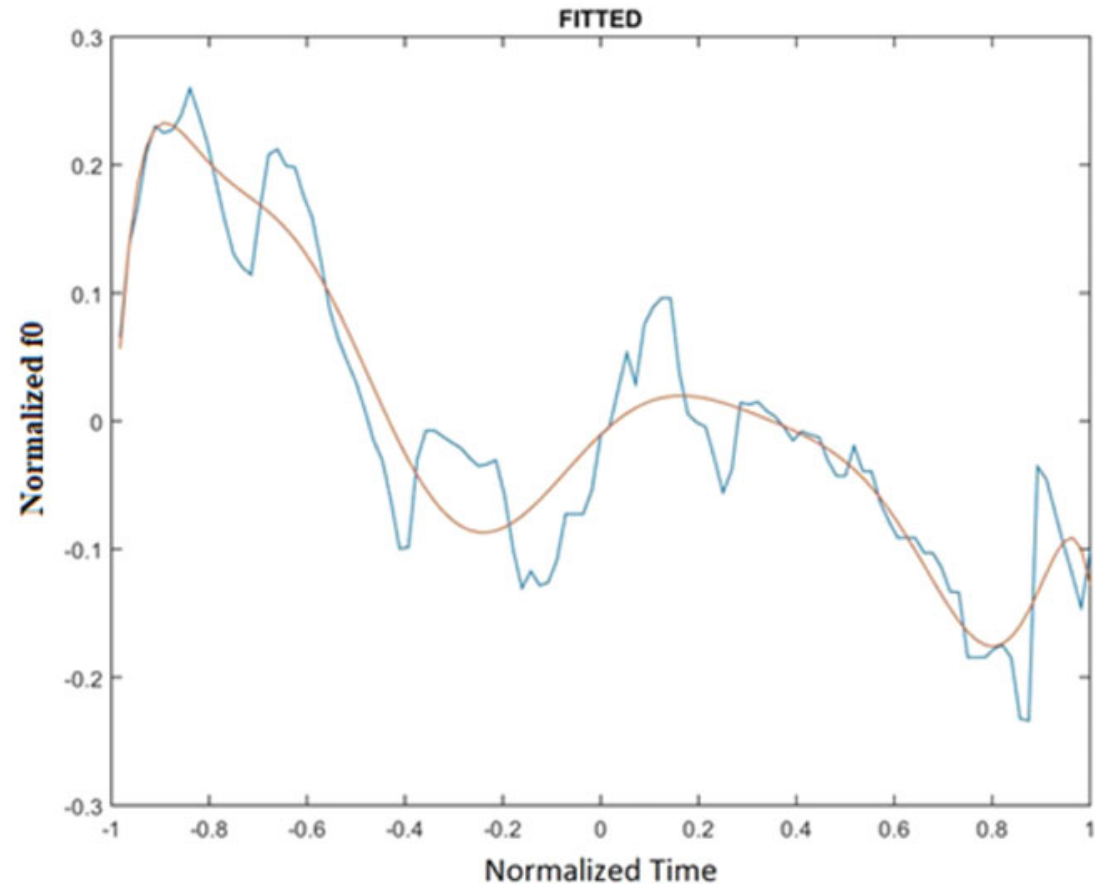

Figure 6 (Colour online) A fitted function with a $d$ of $\sim 0.02$. The smooth (brown) line indicates the fitted function, while the jagged (blue) line represents the normalized $f_{0}$ vector. 
(up to a 25 degree polynomial, beyond which little goodness of fit is gained) if it was not a good enough fit, or decreased the degree if it was possible to lose some coefficients while maintaining accuracy (down to a cubic polynomial at lowest). However, with such a large number of possible coefficients it is difficult to relate each one to a linguistic variable, so in addition to taking the longer fitted functions an additional method was adopted.

The fitted functions were each broken down into trough-to-trough sections to be analyzed. In other words, after fitting, the fitted function was divided into the following segments:

- From the start of the vector to the first trough.

- The interval between each trough and the next.

- From the final trough to the end of the vector.

In terms of the relationship of these trough-to-trough sections to the actual prosody, each section analyzed was roughly equivalent to one ACCENTUAL PHRASE in Japanese (Beckman \& Pierrehumbert 1986, Pierrehumbert \& Beckman 1988, Kubozono 1993). An accentual phrase in (Tokyo) Japanese is characterized by an initial lowering of the pitch, followed by a rise in pitch up to a 'pitch accent', ${ }^{2}$ after which there may be a fall in pitch dependent upon the location of the pitch-accent (Pierrehumbert \& Beckman 1988). Since the point at which pitch begins rising generally marks the beginning of the accentual phrase, the functions analyzed - which start at pitch troughs - should correspond approximately to the accentual phrase structure of the utterance.

Once the portions of the initial fitted function were broken down, cubic polynomials were then fitted to each of those portions of the original (normalized) $f_{0}$ contour that matched the extracted portions of the fitted function, and the orthogonalized coefficients of these new cubic polynomials were analyzed. This resulted in, on average, an excellent function fit, with a mean $d$ of the cubic functions obtained using this method of 0.019 . The four orthogonalized coefficients of those functions can be interpreted as follows (Grabe et al. 2007):

(i) Coefficient 1 maps to the S-shaped 'wiggle' of the function, i.e. how much it moves up and down. Given that this method analyzed from trough-to-trough, this coefficient is unlikely to be high.

(ii) Coefficient 2 corresponds to the breadth of curvature of the function, or how sharply the $f_{0}$ rises towards and falls from the peak. This is broadly equivalent to PITCH DYNAMISM (Henton 1989).

(iii) Coefficient 3 corresponds to the slope of the function, or how steeply the $f_{0}$ rises or falls overall. This relates to the height of the peak of the vector.

(iv) Coefficient 4 (the intercept) corresponds to the average height of the function, (i.e. the mean $f_{0}$ ).

In total, this resulted in 28,841 sets of coefficients. To avoid skewing the data with poorly fitted functions, any function with a $d$ greater than 0.04 was removed from the data set, resulting in 27,118 total coefficient sets to be analyzed. A comparison of the average peak shape of the average functions (obtained by taking the mean of each of the four coefficients for informal and formal speech) can be seen in Figure 7, and a list of the mean orthogonalized coefficients can be seen in Table 4. The average peak shapes seen in Figure 7 should be approximately equivalent to the average $f_{0}$ contour of an accentual phrase in each level of formality.

There are a few visually apparent differences between the average peaks for formal and informal speech. The function representing an accentual phrase in informal speech appears to start lower, and peak higher (related to coefficient 3), while also rising and falling more sharply (coefficient 2). The shape of this function indicates both that the initial pitch lowering observed in accentual phrases in Tokyo Japanese (Pierrehumbert \& Beckman 1988) is more

${ }^{2}$ While a description of the Japanese pitch accent system is outside the scope of this paper, those interested can see work such as Haraguchi (1988), Kubozono $(1993,2011,2012)$ for an overview. 


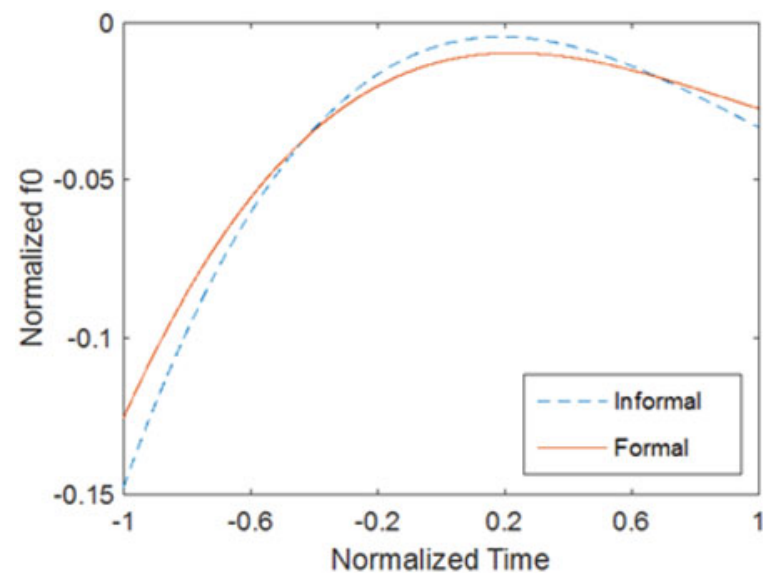

Figure 7 (Colour online) Average peak shape of the fitted functions for informal and formal speech. This is equivalent to the average shape of one accentual phrase in Japanese.

Table 4 List of mean orthogonalized function coefficients.

\begin{tabular}{lllll}
\hline Formality & Coeff. 1 & Coeff. 2 & Coeff. 3 & Coeff. 4 \\
\hline Informal & 0.0285 & -0.0834 & 0.0287 & -0.0072 \\
Formal & 0.0237 & -0.0641 & 0.0252 & -0.0122 \\
\hline
\end{tabular}

All four coefficients are significantly different in formal and informal speech in a generalized logistic mixed-effects model.

Table 5 Results of model comparison for the generalized linear mixed effects model in (6).

\begin{tabular}{lrl}
\hline Coefficient & $\chi^{2}(2)$ & $\operatorname{Pr}\left(>\chi^{2}\right)$ \\
\hline 1 & 4.90 & $<.05$ \\
2 & 16.89 & $<.001$ \\
3 & 6.09 & $<.05$ \\
4 & 16.83 & $<.001$ \\
\hline
\end{tabular}

pronounced in informal speech, and that informal accentual phrases appear to have greater pitch dynamism (Henton 1989).

In order to test the statistical validity of these observations, each coefficient was used as a fixed factor in a binomial generalized linear mixed effects model (GLMM) as shown in (6). All four coefficients were combined in the model, and random intercepts and slopes for each coefficient were taken for the random factor of speaker. A summary of model comparison results for each coefficient is shown in Table 5.

(6) formality $\sim$ coeff $1+$ coeff $2+$ coeff $3+$ coeff 4

$$
+(1+\text { coeff } 1+\text { coeff } 2+\text { coeff } 3+\text { coeff } 4 / \text { speaker })
$$

The results of model comparison showed that all coefficients were significantly different in informal and formal speech. The visual observation of the lower start point and higher peak of the average informal accentual phrase was shown statistically by the significant difference in coefficients 3 and 4 between speech registers (both significantly higher in informal speech). The significance of coefficient 2 meant that $f_{0}$ rose to and fell from the peak more sharply in informal speech which was indicative of greater pitch dynamism in the accentual phrase, 
an attested indicator of greater overall pitch range (Henton 1989, 1995). As the functions were normalized for time, no conclusions can be drawn regarding whether the differences in breadth of curvature is related to the actual lengths of accentual phrases in Japanese. The significance of coefficient 1 is somewhat harder to relate to Figure 7 due to the lack of S-shape in the two functions, but the higher value in informal speech could indicate a greater level of flexibility in the $f_{0}$ contour of an informal accentual phrase in Japanese.

\section{Discussion}

There are several points that arise given the differences and similarities in results seen between this study and previous studies of the prosodic properties of formality and politeness in Japanese (Loveday 1981, Ofuka et al. 2000, Ohara 2001, Ito 2002, Tsuji 2004), as well as to Winter \& Grawunder's (2012) study of Korean and Hübscher et al.'s (2017) study of Catalan.

\section{1 $f_{0}$ and formality in Japanese}

To recap, this study showed that in Japanese conversational speech the mean, SD, and range of $f_{0}$ are all significantly higher in informal speech. This result contrasted with much of the previous literature on the relationship between prosody and formality in Japanese - which had found either mixed results when analyzing $f_{0}$ (Ofuka et al. 2000, Ito 2002) or that $f_{0}$ was higher in polite (formal) speech (Loveday 1981, Ohara 2001, 2004; Tsuji 2004) - and also going against the predictions of the FREQUENCY CODE (Ohala 1984) that higher $f_{0}$ should be a universal linguistic property of polite speech. Conversely, the results largely mirrored those of cross-linguistic studies of Korean (Winter \& Grawunder 2012) and Catalan (Hübscher et al. 2017), indicating some potential cross-linguistic tendencies (if not necessarily universals) in how phonetic parameters such as $f_{0}$ or intensity are used in the expression of formality.

The contrast of the current study with the results of previous related studies of Japanese are somewhat surprising, but can likely be explained by methodological differences. While the current study judged formality post-hoc based on the presence of lexical items or grammatical structures indexical of different levels of formality, previous work judged utterance formality based on either the relative social status of whomever the speaker was addressing (in the case of Ito 2002) or instructed to role-play as if they were addressing (Ofuka et al. 2000, Tsuji 2004). Loveday (1981) is in some ways most similar to the current study in that it evaluated politeness based on the inclusion of certain 'politeness formulae', or specific words or phrases judged to be particularly polite, although the speech was read rather than spontaneous, and there are known differences between the phonetic parameters of read and spontaneous speech in Japanese (Nakamura, Iwano \& Furui 2007). These methodological differences make it difficult to directly compare the current study to previous work on the subject in Japanese, and although the differences in results do cast doubt on the validity of some previous findings, they do not necessarily invalidate them as it is possible that prosody relates to formality differently in different types of speech (i.e. read vs. elicited vs. conversational).

Another point of interest is the potential cross-linguistic validity of the results of this study. The results of this study concerning $f_{0}$ measures were extremely similar to those of Winter \& Grawunder (2012) for Korean, and Hübscher et al. (2017) for Catalan Spanish. Those two studies, along with the current study, contribute to a growing body of evidence against previous claims that high pitch correlating with polite or formal speech is a linguistic universal (Ohala 1984, Brown \& Levinson 1987, Gussenhoven 2002). Hübscher et al. (2017) in particular notes that the similarities in how prosody is used to encode formality may simply be ascribed to similarities between the cultural interpretations of formality and politeness, noting a case where speakers of German from different cultural contexts (Germany and 
Austria) use prosody to express paralinguistic information in different ways (Grawunder, Oertel \& Schwartze 2014). Interestingly however, Japanese is also posited as a contrastive example, where high pitch may be interpreted as a sign of submissiveness (Hübscher et al. 2017: 155) meaning that the fact that this study also found higher $f_{0}$ in informal speech suggests that the issue may be more multi-faceted. This does not invalidate Hübscher et al.'s (2017) observation, but it does show that the explanation may be somewhat reductive. These cultural interpretations may not be entirely static, and variation in speech context (conversational speech, in the case of the current study) may produce unexpected variation in results where prosody is concerned.

In addition to the previously discussed measures of $f_{0}$, this study also conducted a functional data analysis of $f_{0}$ at the approximate level of the accentual phrase. While the analysis of this study was focused primarily on the suprasegmental level (i.e. overall differences in prosody rather than differences at the level of individual segments) which makes the results difficult to interpret in terms of the structure of Japanese, the functional data analysis does allow us to see some ways in which the results are connected to the prosodic structure at the accentual phrase level. As was previously noted, Tokyo Japanese is characterized by an accentual phrase structure where there is an initial lowering of $f_{0}$, followed by a rise to a pitch accent, and finishing with a (possible) final drop in $f_{0}$ (Pierrehumbert \& Beckman 1988). The results of the functional data analysis indicated essentially that the properties of the accentual phrase were exacerbated in informal speech; there was a lower initial start, a higher rise, and a deeper final drop in $f_{0}$, which indicated an overall increase in PITCH DYNAMISM (Henton 1995) in informal speech in Japanese. While this study is limited to showing this difference at the level of the accentual phrase, it is reasonable to expect that similar results of increased pitch dynamism could be seen in other structural contexts, such as for example increased phrase-final $f_{0}$ movement, as was seen in informal speech in Ofuka et al. (2000). It would be useful in future research to investigate similar phenomena in further distinct contexts, which would allow the results to be more easily interpreted in terms of the specific structure of Japanese.

\subsection{Other phonetic parameters and formality in Japanese}

Aside from differences in $f_{0}$, this study also found increased intensity (mean and range), increased articulation rate, and decreased pause rate in informal speech. These results again pattern rather closely with those seen in Winter \& Grawunder (2012) and Hübscher et al. (2017), although in the case of intensity there were some differences with Winter \& Grawunder (2012) in that the SD of intensity was not significant in Japanese, and there were no observed interactions with gender in the current study. The overall results, however, pointed to the possibility that Japanese speakers may also be engaging in what Hübscher et al. (2017) termed 'prosodic mitigation' in formal speech, meaning that formal speech had a more 'subdued' profile - slower, quieter, and more hesitant. In empirical terms, for the data investigated in this study a subdued prosody appeared to be realized both by more a generally more measured pace of speech (lower articulation rate, more pausing) and by a slightly greater degree of flexibility in how speech is paced (higher SD of articulation rate and pause rate in formal speech).

\section{Conclusion}

Overall, this study has demonstrated a significant relationship between prosody and formality in conversational Japanese and provided further evidence against the universality of increased $f_{0}$ as a universal marker of politeness and formality (Ohala 1984). It is difficult to draw any definite conclusions about the cross-linguistic nature of the results, but the similarity of the 
results of this investigation of Japanese to those of similar studies of the unrelated languages of Korean and Catalan Spanish does imply that certain strategies may be used by speakers of many different languages and that the question is worth investigating in further languages and contexts.

This study also leaves open some questions on the more specific nature of how prosody is used by speakers to express different levels of formality in conversation, as the rather large segments that were analyzed (full sentences rather than phrases, words, or moras) precluded a close investigation of exactly how prosody was changing at the segmental level. A more fine-grain investigation could help illuminate further whether the changes in prosody observed in this study are more closely connected to the phonological and morphological structure of Japanese. This study also examined speech data exclusively from speakers of Tokyo Japanese, but an investigation of how the changes in $f_{0}$ seen in this study interact with the pitch accent systems of different dialects could also help provide a better understanding of how the prosodic expression of formality is connected to the overall prosodic structure of Japanese.

\section{Acknowledgements}

I would like to thank Professor John Coleman for his support, and advice regarding the applications of functional data analysis. I would also like to thank Professor Kikuo Maekawa of the National Institute of Japanese Language and Linguistics (NINJAL) for his invaluable support in participant recruitment and data collection for the corpus used in this study, and for assisting with organizing a research visit to Japan. Thanks also to Dr. Hanae Koiso of NINJAL for her advice on corpus structure and interview format. Finally I would like to thank the editor Amalia Arvaniti, and the anonymous reviewers for providing extensive feedback that helped improve this paper by leaps and bounds.

\section{Appendix. List of common interview topics}

MORE FORMAL TOPICS

1. Self-introductions.

2. Subject's work or topic of study.

3. Cultural differences between countries.

4. World travel.

5. Subject's family.
LESS FORMAL TOPICS

1. The subject's and interviewer's hometowns.

2. Favorite sports/teams.

3. Favorite movies or TV shows.

4. Japanese food.

5. Subject's hobbies or leisure activities.

6. Subject's club activities in high school or university.

7. Things to do in Tachikawa city.

\section{References}

Álvarez, Alexandra \& María A. Blondet. 2003. Cortesía y prosodia: un estudio de la frase cortés en el español de Mérida (Venezuela). In Esther Herrera \& Pedro Martín Butragueño (eds.), La tonía: Dimensiones fonéticas y fonológicas, 319-330. México: D. F El Colegio de México,

Anderson, Anne H., Miles Bader, Ellen G. Bard, Elizabeth Boyle, Gwyneth Doherty, Simon Garrod \& Catherine Sotillo. 1991. The HCRC map task corpus. Language and Speech 34(4), 351-366.

Aono, Motoko, Akira Ichikawa, Hanae Koiso, Shinji Sato, Makiko Naka, Syun Tutiya \& Kenji Yagi. 1994. The Japanese map task corpus: An interim report. Spoken language understanding and discourse processing - Japanese Society for Artificial Intelligence, 25-30.

Bates, Douglas, Martin Maechler, Ben Bolker \& Steve Walker. 2015. Fitting linear mixed-effects models using Ime4. Journal of Statistical Software 67(1), 1-48.

Beckman, Mary E. \& Janet B Pierrehumbert. 1986. Intonational structure in Japanese and English. Phonology 3(1), 255-309. 
Bolker, Ben, Mollie E. Brooks, Connie J. Clark, Shane W. Geange, John R. Poulsen, M. Henry H. Stevens \& Jada-Simone S. White. 2009. Generalized linear mixed models: A practical guide for ecology and evolution. Trends in Ecology \& Evolution 24(3), 127-135.

Brown, Lucien, Bodo Winter, Kaori Idemaru \& Sven Grawunder. 2014. Phonetics and politeness: Perceiving Korean honorific and non-honorific speech through phonetic cues. Journal of Pragmatics 66, 45-60.

Brown, Penelope \& Stephen C. Levinson. 1978. Universals in language usage: Politeness phenomena. In Esther N. Goody (ed.), Questions and politeness: Strategies in social interaction, 56-311. Cambridge University Press.

Brown, Penelope \& Stephen C. Levinson. 1987. Politeness: Some universals in language usage. Cambridge: Cambridge University Press.

Cook, Haruko M. 1998. Situational meanings of Japanese social deixis: The mixed use of the masu and plain forms. Journal of Linguistic Anthropology 8(1), 87-110.

Den, Yasuharu \& Mika Enomoto. 2007. A scientific approach to conversational informatics: Description, analysis, and modeling of human conversation. In Toyoaki Nishida (ed.), Conversational informatics: An engineering approach, 307-330. Hoboken, NJ: John Wiley \& Sons.

Fujisaki, Hiroya \& Keikichi Hirose. 1984. Analysis of voice fundamental frequency contours for declarativesentences of Japanese. Journal of the Acoustical Society of Japan (E), 5(4), 233-242.

Gahl, Susanne. 2008. Time and thyme are not homophones: The effect of lemma frequency on word durations in spontaneous speech. Language 84(3), 474-496.

Guion, Susan. 1995. Word frequency effects among homonyms. Texas Linguistic Forum 35, 103-116.

Grabe, Esther, Greg Kochanski \& John Coleman. 2007. Connecting intonation labels to mathematical descriptions of fundamental frequency. Language and Speech 50(3), 281-310.

Grawunder, Sven, Marianne Oertel \& Cordula Schwarze. 2014. Politeness, culture, and speaking task: Paralinguistic prosodic behavior of speakers from Austria and Germany. Proceedings of the International Conference on Speech Prosody, Dublin, Ireland, 159-163.

Gussenhoven, Carlos. 2002. Intonation and interpretation: Phonetics and phonology. Speech Prosody 2002: Proceedings of the First International Conference on Speech Prosody, 47-57.

Haraguchi, Shosuke. 1988. Pitch accent and intonation in Japanese. In Harry van der Hulst \& Norval Smith (eds.), Autosegmental studies on pitch accent, 123-150. Berlin: Walter de Gruyter.

Harrington, Jonathan, Sallyanne Palethorpe \& Catherine J. Watson. 2007. Age-related changes in fundamental frequency and formants: A longitudal study of four speakers. Interspeech 2007, 27532756.

Henton, Caroline G. 1989. Fact and fiction in the description of female and male pitch. Language \& Communication 9(4), 299-311.

Henton, Caroline G. 1995. Pitch dynamism in female and male speech. Language \& Communication 15(1), 43-61.

Hidalgo Navarro, Antonio \& Adrián Cabedo Nebot. 2014. On the importance of the prosodic component in the expression of linguistic im/politeness. Journal of Politeness Research 10(1), 5-27.

Hinds, John. 1976. Japanese discourse structure. Tokyo: Kaitakusha.

Hinds, John. 1978. Conversational structure: An investigation based on Japanese interview discourse. Problems in Japanese Syntax and Semantics 79, 79-121.

Hübscher, Iris, Joan Borràs-Comes \& Pilar Prieto. 2017. Prosodic mitigation characterizes Catalan formal speech: The frequency code reassessed. Journal of Phonetics 65, 145-159.

Ide, Sachiko. 1982. Japanese sociolinguistics politeness and women's language. Lingua 57, 357-385.

Ide, Sachiko. 1989. Formal forms and discernment: Two neglected aspects of universals of linguistic politeness. Multilingua: Journal of Cross-cultural and Interlanguage Communication 8(2-3), 223248.

Irvine, Judith T. 1979. Formality and informality in communicative events. American Anthropologist 81(4), $773-790$.

Ito, Miko. 2002. Japanese politeness and suprasegmentals: A study based on natural speech materials. Speech Prosody 2002, 415-418. 
Keelan, Evanini, Catherine Lai \& Klaus Zechner. 2010. The importance of optimal parameter setting for pitch extraction. Proceedings of Meetings on Acoustics 160ASA, vol. 11, no. 1, 060004.

Kubozono, Haruo. 1993. The organization of Japanese prosody. Tokyo: Kurosio.

Kubozono, Haruo. 2011. Japanese pitch accent. The Blackwell Companion to Phonology, vol. 5, 28792907.

Kubozono, Haruo. 2012. Varieties of pitch accent systems in Japanese. Lingua 122(13), 1395-1414.

Kubozono, Haruo (ed.). 2015. Handbook of Japanese phonetics and phonology, vol. 2. Berlin: Walter de Gruyter.

Labov, William. 1972. Sociolinguistic patterns. Philadelphia, PA: University of Pennsylvania Press.

Lin, Hsin-Yi, John T. Kwock-Ping \& Janice Fon. 2006. An acoustic study on the paralinguistic prosody in the politeness talk in Taiwan Mandarin. Proceedings of ISCA Tutorial and Research Workshop on Experimental Linguistics, Athens, Greece, 173-176.

Loveday, Leo. 1981. Pitch, politeness and sexual role: An exploratory investigation into the pitch correlates of English and Japanese politeness formulae. Language and Speech 24, 71-89.

Maekawa, Kikuo. 2003. Corpus of spontaneous Japanese: Its design and evaluation. ISCA \& IEEE Workshop on Spontaneous Speech Processing and Recognition, 2003, Tokyo, Japan, 7-12.

Makino, Seiichi. 1983. Speaker/listener-orientation and formality marking in Japanese. GENGO KENKYU (Journal of the Linguistic Society of Japan) 84, 126-145.

Matsumoto, Yoshiko. 1988. Rexamination of the universality of face: Politeness phenomena in Japanese. Journal of Pragmatics 12, 403-426.

Moore, Brian C. \& Brian R. Glasberg. 1983. Suggested formulae for calculating auditory-filter bandwidths and excitation patterns. The Journal of the Acoustical Society of America 74(3), 750-753.

Nakamura, Masanobu, Koji Iwano \& Sadaoki Furui. 2007. Differences between acoustic characteristics of spontaneous and read speech and their effects on speech recognition performance. Computer Speech and Language 22, 171-184.

Nolan, Francis. 2003. Intonational equivalence: An experimental evaluation of pitch scales. Proceedings of the 15th International Congress of Phonetic Sciences (ICPhS XV), Barcelona, 771-774.

Ofuka, Etsuko, Denis J. McKeown, Mitch Waterman \& Peter Roach. 2000. Prosodic cues for rated politeness in Japanese speech. Speech Communication 32, 199-217.

Ogino, Tsunao \& Yin Shao Hong. 1992. Nihongo onsei no teineisa ni kansuru kenkyuu [A study on politeness in Japanese speech]. In Takeo Kunihiro (ed.), Nihongo intonation no jittai to bunseki [The state-of-the-art and analysis of Japanese intonation], 215-258. Tokyo: Monbushou.

Ohala, John J. 1984. An ethological perspective on common cross-language utilization of f0 of voice. Phonetica 41, 1-16.

Ohara, Yumiko. 2001. Finding one's voice in Japanese: A study of the pitch levels of L2 users. In Aneta Pavlenko, Adrian Brackledge, Ingrid Piller \& Marya Teutsch-Dwyer (eds.), Multilingualism, second language learning, and gender, 231-254. New York: Mouton de Gruyter.

Ohara, Yumiko. 2004. Prosody and gender in workplace interaction: Exploring constrains and resources in the use of Japanese. In Shigeko Okamoto \& Janet Shibamoto Smith (eds.), Japanese language, gender, and ideology: Cultural models and real people, 222-239. New York: Oxford University Press.

Okamoto, Shigeko. 1999. Situated politeness: Manipulating honorific and non-honorific expressions in Japanese conversations. Pragmatics 9(1), 51-74.

Pierrehumbert, Janet B. \& Mary E. Beckman. 1988. Japanese tone structure (Linguistic Inquiry Monographs 15). Cambridge, MA: MIT Press.

Pizziconi, Barbara. 2002. Re-examining Japanese politeness, face, and the Japanese language. Journal of Pragmatics 35, 1471-1506.

R Core Team. 2017. R: A language and environment for statistical computing. Vienna: R Foundation for Statistical Computing. https://www.R-project.org/.

Ramsay, James O. 2006. Functional data analysis. Hoboken, NJ: John Wiley \& Sons.

Sherr-Ziarko, Ethan. 2016. Acoustic properties of formality in conversational Japanese. Interspeech 2016, $1285-1289$.

Sreetharan, Cindy. 2004. Students, sarariiman (PL), and seniors: Japanese men's use of the 'manly' speech register. Language in Society 33, 81-107. 
Tsuji, Akiko. 2004. The case study of high pitch register in English and in Japanese: Does high pitch register relate to politeness? Seijo English Monographs 37, 227-260.

Venditti, Jennifer J., Sun-Ah Jun \& Mary E. Beckman. 2014. Structures in Japanese, Korean, and English. In James L. Morgan \& Katherine Demuth (eds.), Signal to syntax: Bootstrapping from speech to grammar in early acquisition, 287-311. Mahwah, NJ: Erlbaum.

Winter, Bodo \& Sven Grawunder. 2012. The phonetic profile of Korean formal and informal speech registers. Journal of Phonetics 40, 808-815.

$\mathrm{Xu}$, Yi. 2013. ProsodyPro: A tool for large-scale systematic prosody analysis. Proceedings of Tools and Resources for the Analysis of Speech Prosody (TRASP 2013), Aix-en-Provence, France, 7-10.

Zwicker, Eberhard. 1961. Subdivision of the audible frequency range into critical bands (Frequenzgruppen). The Journal of the Acoustical Society of America 33(2), 248-248. 